\title{
EFFECTS OF MUSIC ON PHYSIOLOGICAL RESPONSE
}

\author{
Janet E. Landreth \\ Hobart F. Landreth*
}

\begin{abstract}
For this study the heart rates of twenty-two members of a college-level music appreciation class were recorded while students listened to the first movement of Beethoven's fifth symphony. The measurements were taken at three different times over a six-week period before, during, and after experimental treatment. Experimental treatment consisted of either audiotutorial tapes or repetitive listening sessions devised for specific musical-ability groups. The same test music was used throughout the entire study to determine the effects of learning and repetitive exposure on heart rate response. A control group had no further exposure to the test music during the study. Stable segments of the test music provoked tachycardia (elevated heart rate) in the subjects, while alternating segments produced bradycardia (lowered heart rate). Heart rate response to music was found to be linked with the presence or absence of learning.
\end{abstract}

Key words: aesthetic experience, aural discrimination, heart rate, learning theory, testing.

Music appreciation has been described by Machlis as an interaction of the physical, emotional, and intellectual levels of listening response. ${ }^{1}$ These levels of listening response involve sensual reactions to rhythmic energy, imaginary associations conveyed by music, and aesthetic evaluations of musical design and performance. The understanding of music appreciation has been impeded by the complexity of these factors.

Diserens reviewed many of the experiments designed to measure physiological responses to simple musical stimuli-for example,

* This article is dedicated to the memory of Hobart F. Landreth, who lost his life in a canoeing accident on March 4, 1973.

${ }^{1}$ Joseph Machlis, The Enjoyment of Music (New York: W. W. Norton and Company, 1955). 
isolated tones, musical intervals, and chords. ${ }^{2}$ Other studies have demonstrated the effects of musical stimuli on such physiological parameters as pupillary reflexes, gastric motility, and muscle tonus. ${ }^{3}$ Investigations by Davies, Phares, Ries, Schrift, and Winold measured the effects of music on variations in galvanic skin resistance. ${ }^{4}$ Hyde and Scalapino noted variations in heart rate and blood pressure corresponding to different types of musical selections, and Ellis and Brighouse suggested that music causes an increase in heart rate. ${ }^{5}$ These studies of heart rate response refer to total heart rate for a particular musical selection and do not consider heart rate changes that occur within segments of music. The influence of a greater knowledge of a particular composition on physiological parameters has not been measured.

This study was a preliminary investigation attempting to measure complex physiological parameters associated with listener response at the college level. ${ }^{6}$ Inclusion of such variables as intelligence, musical aptitude, and developmental learning in a study of this nature, coupled with the exigency of both musical and physiological data analysis, calls for an interdisciplinary approach to the experimental design.

\section{Design and Procedure}

Members of a college introductory music class served as experimental subjects. These twenty-two general education students came from various backgrounds, and none were accomplished musicians. Musical experiences of the subjects ranged from individuals with a few years of private instruction on various instruments to those with no formal musical

\footnotetext{
${ }^{2}$ C. M. Diserens, "Reactions to Musical Stimuli," The Psychological Bulletin, Vol. 20 (1923), pp. 173-199.

${ }^{3}$ W. Sears, "The Effect of Music on Muscle Tonus," Music Therapy, Vol. 7 (1958), pp. 250-261; F. E. Slaughter, "The Effect of Musical Stimuli on Normal and Abnormal Subjects, as Indicated by Pupillary Reflexes," Music Therapy, Vol. 3 (1954), pp. 246250; V. M. Wilson, "Variations in Gastric Motility Due to Musical Stimuli," Music Therapy, Vol. 6 (1957), pp. 243-249.

${ }^{4}$ R. C. Davies, "Modifications of the Galvanic Reflex by Daily Repetition of a Stimulus," Journal of Experimental Psychology, Vol. 17 (1934), pp. 504-535; M. L. Phares, "Analysis of Musical Appreciation by Means of PGR (Physio-Galvanic Reflex) Technique," Journal of Experimental Psychology, Vol. 17 (1934), pp. 119-140; H. A. Ries, "GSR and Breathing Amplitude Related to Emotional Reactions to Music," Psychological Science, Vol. 14 (1969), pp. 62-64; D. C. Schrift, "The Galvanic Skin Response to Two Contrasting Types of Music," Music Therapy, Vol. 6 (1957), pp. 235-239; C. A. Winold, The Effects of Changes in Harmonic Tension upon Listener Response (doctoral dissertation, Indiana University, 1963).

5 D. S. Ellis and G. Brighouse, "Effects of Music on Respiration and Heartrate," American Journal of Psychology, Vol. 65 (1952), pp. 39-47; E. Hyde and W. Scalapino, "Influence of Music on Electro-Cardiograms and Blood Pressure," American Journal of Psychology, Vol. 46 (1918), pp. 35-38.

${ }^{6}$ Acknowledgement goes to the music department of Southwestern State College, Weatherford, Oklahoma, for the experimental subjects in this study; appreciation also is extended to Freda Johnson, Gina Davidson, Mary Wilson, Gary Schnell, and Robert Glidden.
} 


\section{6/JRME}

training. None of the subjects favored classical music in their listening preference.

The musical aptitude test was administered to the class at the first regular meeting. Each student then attended a laboratory session, where his baseline physiological parameters were recorded while he listened to the allegro movement of Beethoven's fifth symphony. The subjects were divided into four groups on the basis of their performance on the aptitude test. Experimental treatment was initiated at the start of the second week of class. The musical aptitude test used in this study determined the subject's ability to recognize pitches, melodic patterns, major and minor tonalities, key centers, metric units, rhythmic patterns, instrumental timbres, and musical styles. It was a fifty-point test specifically designed to evaluate the listener's perception of aural stimuli. Although a standardized test was not used, the devised test was readministered to each student at the end of the semester. Both sets of test scores were compared to determine the test's reliability.

Each week, group one (highest scores) and group two (lowest scores) heard audiotutorial tapes containing indepth studies of the test music and its composer. The instructional tapes were developed to focus attention on three basic aspects of Beethoven and his works: (1) general characteristics of his life and music, (2) perspectives of the classical period, and (3) form and thematic development. The allegro movement of Beethoven's fifth symphony was discussed throughout the tapes, along with excerpts from other symphonies and piano sonatas. The entire first movement of the fifth symphony was played to conclude each tape.

Group three (low average scores) attended weekly listening sessions. In each session, group three heard the test music five times but received no instructions. Group four (high average scores) served as the control group by participating in the regular class activities. These classes were organized lecture-demonstrations designed to survey music from the Baroque period to the twentieth century.

At midterm the same physiological determinations were made as each student listened to the same test music. The experimental treatment was continued during the second half of the course, and a final series of physiological recordings were made as the subjects listened to the test music on the last day of the semester. The Wechsler Adult Intelligence Scale (WAIS) was given to each student during the semester, and the scores were used for comparison. Testing was conducted by an educational specialist, Freda Johnson, in the Counseling Center of Southwestern State College, Weatherford, Oklahoma. The examiner chose the WAIS to attempt to attenuate any bias resulting from reading deficiencies.

Various physiological parameters-electrocardiogram (ECG), electroencephalogram (EEG), galvanic skin resistance (GSR), and respirationwere recorded on a Gilson (M5P) polygraph while subjects listened to a tape recording of the test music. Standardized recording techniques and preparations were used. Each student was prepared individually, and each session was conducted in a quiet, isolated laboratory room with 
the subject at rest. A five-minute pretest recording was made for each individual before the test music was turned on during each session. The pretest recording was used as a standard for comparison in each of the three sessions for each student. The data from the research are delimited to the effects of music on heart rate response. The test music was divided into eight segments on the basis of content (see Table I). Each student's mean pretest heart rate for the day was compared to his mean heart rate within each test music segment.

The Pearson product-moment coefficient was used to test reliability both within the pretest and among pre- and posttest scores for the nonstandardized musical aptitude test. A one-way analysis of variance indicated differences in total class response to each test music section. The significant $\mathrm{F}$ value was further investigated by using the $t$ test. The MannWhitney $U$ test was used as a preliminary measure to indicate grouped differences in heart rate response (response one and three). In testing for heart rate changes among the three test intervals, an analysis of covariance with multiple values of $\mathrm{X}$ was used. Regression lines were established for each group within each of the eight segments of the test music.

\section{Results}

The Pearson product-moment coefficient proved the musical aptitude test reliable at the .6084 level by comparing pre-and posttest scores and at the .6964 level by running a random sampling of the pretest scores. Out of fifty possible points, total class scores on the musical aptitude test ranged from 15 to 35 . Intelligence quotient scores for the total class ranged from 94 to 129. Although the musical aptitude scores were used as the only criterion for group placement, a correlation appeared between IQ and musical ability of these subjects. Group means from the IQ and musical aptitude tests were different between the first and second experimental-learning groups. The mean scores of group three were similar to those of group two, but the experimental treatment for group three merely consisted of repetitive exposure to the test music. Mean scores for group four were average; this group had no contact with the test music during the study (see Table 2).

A one-way analysis of variance in heart rate response to the eight musical sections proved a significant difference at the .001 probability level. This procedure involved cumulative heart rate response, that is, total number of test intervals (three). Using the $t$ test, significant differences in heart rate response were found between pairs of certain musical sections. Significant differences in heart rate response occurred between sections that exhibited marked rhythmical, textural, and dynamic differences (see Table 1). Tachycardia (elevated heart rate) and bradycardia (lowered heart rate) are indicated by the deviation mean scores for each musical section, as shown in Table 2. The deviations are predominately negative for all groups within sections C, D, E, and G. Within sections $A, B, F$, and $H$, the deviations are essentially positive. The range of 
Table 1

Description of the Eight Test Music Sections

\begin{tabular}{|c|c|c|}
\hline $\begin{array}{l}\text { Characteristic } \\
\text { Type }\end{array}$ & Section & Description \\
\hline Stable & A & $\begin{array}{l}21 \text { measures } \\
\text { Main theme (FF), instrumental imitation of main } \\
\text { theme, crescendo, return of main theme. }\end{array}$ \\
\hline Stable & B & $\begin{array}{l}36 \text { measures } \\
\text { Repetition of opening measures at higher pitch. }\end{array}$ \\
\hline Alternating & $\mathrm{C}$ & $\begin{array}{l}13 \text { measures } \\
\text { Fast, harsh repetition of loud chord by full orchestra. } \\
\text { Rest. Sudden repetition of forte chord at higher pitch. } \\
\text { Rest. Crescendo. Rest. Full orchestra (FF chords). }\end{array}$ \\
\hline Alternating & $\mathrm{D}$ & $\begin{array}{l}49 \text { measures } \\
\text { Imitative setting of main theme; syncopations and ac- } \\
\text { cents. Timing alteration; one note per measure. } \\
\text { Diminuendo. }\end{array}$ \\
\hline Alternating & E & $\begin{array}{l}22 \text { measures } \\
\text { FF chords interrupt preceding section. Sudden pianis- } \\
\text { simo. Forte chord interruption. First two measures of } \\
\text { the recapitulation. }\end{array}$ \\
\hline Stable & $\mathrm{F}$ & $\begin{array}{l}20 \text { measures } \\
\text { Full recapitulation. }\end{array}$ \\
\hline Alternating & G & $\begin{array}{l}\text { One measure } \\
\text { Oboe solo, suspension of rhythmic drive. }\end{array}$ \\
\hline Stable: Alternating & $\mathrm{H}$ & $\begin{array}{l}24 \text { measures } \\
\text { Codetta, main theme returns. Last } 12 \text { measures marked } \\
\text { by sudden breaks and reoccurring main theme. }\end{array}$ \\
\hline
\end{tabular}

individual heart rate responses was -54 to +63 (deviations from mean). Of the 528 segments, there were only 21 segments in which the subjects did not demonstrate a change in cardiac response.

To determine if significant heart rate changes occurred as a result of increased knowledge of the symphony or repeated exposure to the music, a nonparametric procedure was used to compare the four experimental groups in all musical segments. The Mann-Whitney $U$ test demonstrated a significant difference in response between groups one (learning) and four (no learning) in section A of the music. No significant differences were found between groups two (learning) and three (repetitive exposure).

The regression analysis, depicted in Figure 1, indicated that group four was the only group to exhibit a regression line with a positive slope in all eight sections of the test music. Group one showed a positive slope in sections $\mathrm{A}, \mathrm{B}$, and $\mathrm{C}$; but in sections $\mathrm{D}$ through $\mathrm{H}$, the slope was negative. The slope of group two was negative in section $\mathrm{H}$ but positive in all other sections. The regression line of group three demonstrated a positive slope in section $\mathrm{D}$ but a negative slope in all other sections. The 
Landreth/9

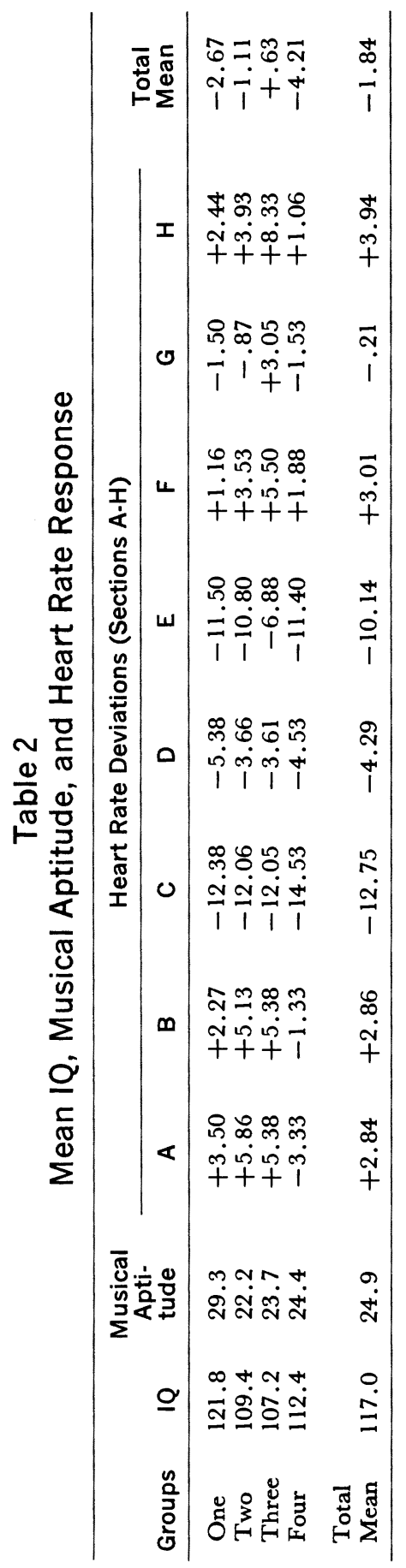




\section{0/JRME}
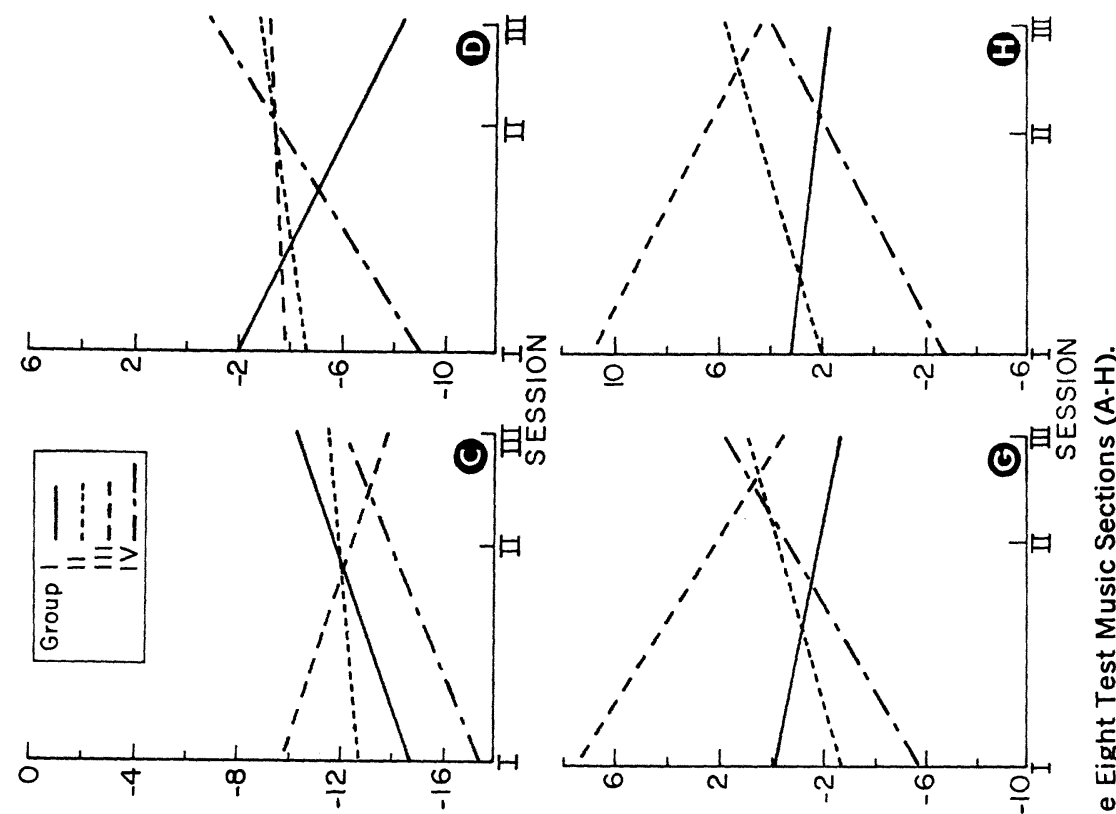

$\exists 9 N \forall H \supset \quad \exists \perp \forall Y \quad \perp \forall \forall \exists H$

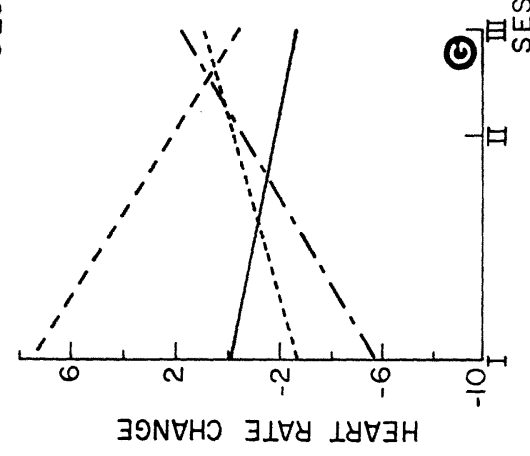

U

ป

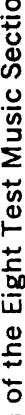
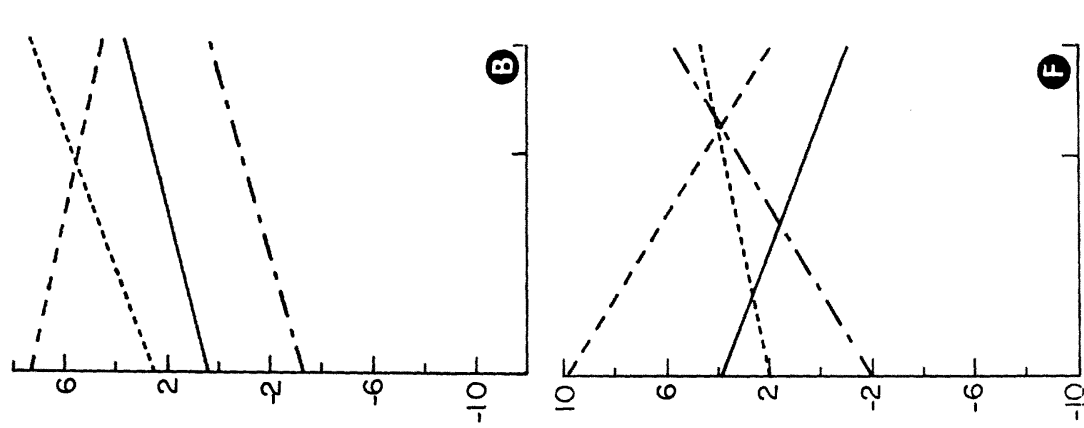

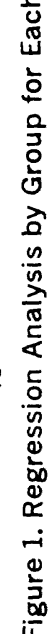

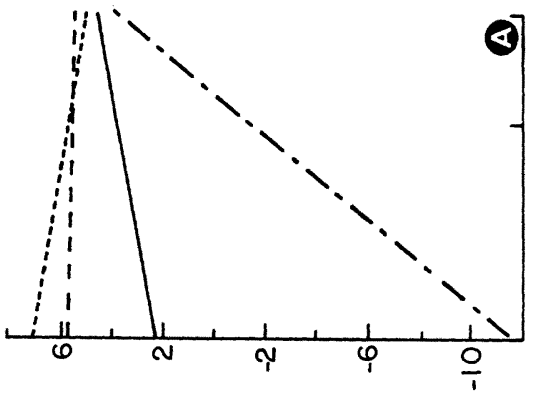

$\exists \fallingdotseq N \forall H \supset \quad \exists \perp \forall Y \perp \forall \forall \exists H$

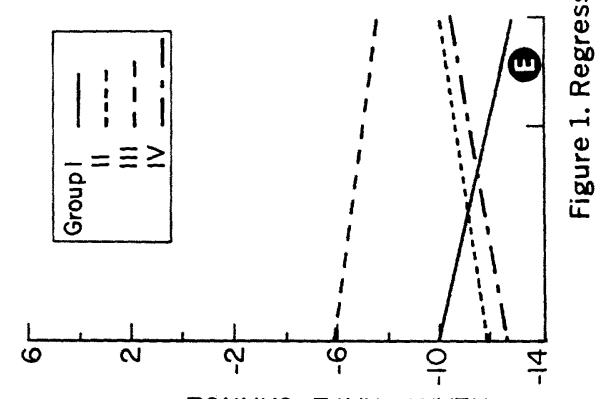

$\exists 9 N \forall H O \quad \exists \perp \forall Y \perp \forall \forall \exists H$ 
regression line of group four in section A proved to be significantly different from the other groups at the .05 probability level. The regression lines of group four (B, F, H) and group two (B, H) approached this same level of significance. Variance in the regression analysis approached significance with group four in sections A, D, and G; this was not true for any of the other groups.

\section{Discussion}

Results of this study indicated that differing musical settings of a composition provoked significant heart rate changes by either slowing down the beat (bradycardia) or speeding up the beat (tachycardia). Test-music segments that were characterized by driving and insistent rhythm, mounting sequential interplay, and progressive dynamic intensity (sections A, B, F) produced tachycardia in the listener. Conversely, musical segments with eminent changes in rhythm, texture, and dynamics produced bradycardia in the experimental subjects. Investigations of emotional arousal have been limited; but there are indications, as shown by Henry and Meehan, that there is a conscious behavioral component involved with automatic adjustments that is not recognized by the organism. ${ }^{7}$ This component may have influenced the heart rate in the present study's subjects.

Ellis and Brighouse concluded that music did not affect significantly the listener's heart rate. ${ }^{8}$ Their study was designed to compare cardiac rates before, during, and after musical stimulation. In the present study, the heart rate was measured during the entire musical selection and during eight distinctive test music sections. The summation of accelerated and decelerated heart rates found during the eight musical sections would have resulted in no apparent change had the heart rate been examined for the entire musical selection. Hyde and Scalapino also found that the total heart rate increases or decreases in response to music, depending on the type of composition played. ${ }^{9}$

Heart rate response to music appears to be linked with the presence or absence of learning and repetitive exposure to music. Only 3.1 percent (14 of 352) of the segments of the second and third listening session involved no heart rate change, and 50 percent of those subjects were in group four. The effects of learning and exposure on heart rate response to music is demonstrated further by the regression analysis. The regression lines plotted for group four either approached significance or were significantly different from the other three groups that received experimental treatment.

The listener's response to soundwave changes in frequency, amplitude, and timbre is possible through a limited number of mechanisms. The

\footnotetext{
${ }^{7}$ J. P. Henry and J. P. Meehan, The Circulation (Chicago: Yearbook Medical Publishers, Inc., 1971).

${ }^{8}$ Ellis and Brighouse.

${ }^{9}$ Hyde and Scalapino.
} 


\section{2/JRME}

sound may stimulate involuntary centers in the central nervous system that, in turn, bring about physiological reactions that later become involved with conscious thought. On the other hand, the music may be transmitted first to the higher levels of the listener's brain, where the sound becomes involved with emotion and abstract thought before affecting the physiology. The third possibility is the most likely, as it involves a combination of the other two. Results of this study demonstrate that physiological responses of the listener can be affected by his increased knowledge and understanding of a musical score. This does not necessarily suggest any change in his level of music appreciation. Heart rate is only one aspect of physiological response; other parameters warrant investigation, for example, EEG, GSR, and respiration. In future studies, specific efforts should be made to increase the sample size and the number of response testings. Pretest activities of the subjects should be controlled and attempts should be made to equalize the intervals between tests.

University of Oklahoma

Norman, Oklahoma 